\title{
Association of placental Plasmodium falciparum parasitaemia with maternal and newborn outcomes in the periurban area of Bobo-Dioulasso, Burkina Faso
}

\author{
MAMOUDOU CISSE ${ }^{1,2}$, A. HAMA DIALLO ${ }^{3}$, D. ADOLPHE SOMÉ ${ }^{4}$, ARMEL PODA ${ }^{5}$, \\ A. GORDON AWANDARE ${ }^{6}$ and T. ROBERT GUIGUEMDÉ ${ }^{1,2}$ \\ ${ }^{1}$ Department of Biomedical Sciences, Centre MURAZ, Bobo-Dioulasso, Burkina Faso \\ ${ }^{2}$ Department of Parasitology and Mycology, Université Polytechnique de Bobo-Dioulasso, Bobo-Dioulasso, Burkina Faso \\ ${ }^{3}$ Department of Public Health, Centre MURAZ, Bobo-Dioulasso, Burkina Faso \\ ${ }^{4}$ Department of Gynaecology and Obstetrics, Centre Hospitalier Universitaire Souro Sanou, Bobo-Dioulasso, Burkina Faso \\ ${ }^{5}$ Department of Infectious Diseases, Centre Hospitalier Universitaire Souro Sanou, Bobo-Dioulasso, Burkina Faso \\ ${ }^{6}$ University of Ghana, West African Centre for Cell Biology of Infectious Pathogens, Accra, Ghana
}

(Received 26 May 2016; revised 11 August 2016; accepted 15 August 2016)

S U M MAR Y

The prevalence of placental malaria and its impact on maternal and newborn outcomes have been poorly documented in periurban settings of Burkina Faso. Peripheral and placental blood from 320 mothers, and cord blood from their newborns were collected through a cross-sectional study and used to prepare thick and thin blood films. Maternal haemoglobin concentration and birthweight were also measured. The overall malaria parasitaemia prevalence in peripheral, placental and cord blood was of $17 \cdot 2,9 \cdot 1$ and $0 \cdot 9 \%$, respectively. Plasmodium falciparum was the sole species found in all cases and the mean parasite density in placental blood was $4 \cdot 5 \pm 0 \cdot 8$ parasites $\mu \mathrm{L}^{-1}$. Primigravida (aOR: 3.5; 95\% CI $(1 \cdot 1-11 \cdot 2)$ ) and women who did not use a bed net (aOR: $2 \cdot 6 ; 95 \%$ CI $(1 \cdot 1-6 \cdot 3)$ ), were at higher odds of placental malaria infection. Women with placental parasitaemia were at increased odds of maternal anaemia (aOR: 3.1; 95\% CI $(1 \cdot 3-7 \cdot 4)$ ). There was no odds difference for LBW between mothers with placental parasitaemia and those without. Placental malaria parasitaemia resulted in a significant mean birthweight reduction of $200 \mathrm{~g}$. Placental malaria infection is higher in primigravida. Use of insecticide-treated bed nets should be therefore emphasized for primigravida during the first antenatal care visit.

Key words: Placental malaria, maternal anaemia, congenital malaria, birthweight, Burkina Faso.

\section{INTRODUCTION}

Malaria during pregnancy is still a major public health problem in sub-Saharan Africa. Indeed in this region, approximately 25 million pregnant women are at risk of Plasmodium falciparum infection every year, and about $25 \%$ of women carry placental P. falciparum infection at the time of delivery (Desai et al. 2007). Plasmodium falciparum infection in pregnancy may result in parasite sequestration in maternal placental vascular space (Steketee et al. 2001), this phenomenon often causes adverse outcomes such as intrauterine growth restriction, preterm delivery, low birthweight (LBW), stillbirth, early neonatal death and maternal anaemia (Steketee et al. 2001; Desai et al. 2007). The proportion of severe anaemia during pregnancy attributable to malaria is estimated to be $26 \%$, irrespective of maternal gravidities (Desai et al. 2007). In areas of high malaria transmission in Africa, the risk of LBW approximately doubles if women have placental malaria (Guyatt and Snow, 2004).

* Corresponding author. Centre MURAZ, Bobo-Dioulasso, 01 BP 390, Burkina Faso. E-mail: mamoudou.cisse@centremuraz.bf
The World Health Organization (WHO) recommends the administration of intermittent preventive treatment with sulfadoxine-pyrimethamine (IPTp$\mathrm{SP})$, the use of insecticide-treated nets and the effective management of clinical cases as relevant strategies to reduce the burden of malaria and improve birth outcomes (WHO, 2004). Recently, the WHO has recommended that SP should be provided at each scheduled focused antenatal care (ANC) visit in the second and third trimesters (WHO, 2012).

Burkina Faso, a poor country located in West Africa is holoendemic for malaria. Many studies have reported placental $P$. falciparum malaria with a prevalence ranging from $15 \cdot 2$ to $22 \cdot 7 \%$ in rural areas (Sirima et al. 2006; Gies et al. 2008, 2009; Tiono et al. 2009) and from 4.7 to $13 \%$ in urban areas (Molez et al. 1992; Gazin et al. 1994; Bamba et al. 2013). However, in the periurban settings, there are few and old data on the prevalence of placental malaria including Bobo-Dioulasso, the country's second largest city (Molez et al. 1992; Gazin et al. 1994; Bamba et al. 2013). Furthermore, the effects of placental malaria on maternal and newborn outcomes have been poorly documented in this town and the present study sought to fill this knowledge gap.

Parasitology Open (2016), Vol. 2, e15; page 1 of 8 . (C) Cambridge University Press 2016. This is an Open Access article, distributed under the terms of the Creative Commons Attribution licence (http://creativecommons.org/licenses/by/4.0/), which permits unrestricted re-use, distribution, and reproduction in any medium, provided the original work is properly cited. 
METHODS

\section{Study site}

This study was conducted in Bobo-Dioulasso, a town located $365 \mathrm{~km}$, South-West of Ouagadougou, the capital city of Burkina Faso. There are an estimated to 800000 inhabitants of Bobo-Dioulasso with farming and trading as main economic activities. The site is an area of high malaria transmission season from May to November. The average entomological inoculation rate is about 63 infectious bites per person per year in the periurban area of Bobo-Dioulasso (Diabaté, 2003).

\section{Study design}

We conducted a cross-sectional study from September to December 2010 in the primary health facilities of Kua and Lafiabougou both located in the periurban area of Bobo-Dioulasso.

\section{Participants}

Study participants were women attending the two primary health facilities for delivery. Women with alive singleton births were included in the study; exclusion criteria were women with pathological pregnancies that could affect the placenta such as retro placental hematoma placenta previa.

\section{Collection of personal data and blood samples}

Information on maternal baseline (age, education, parity), utilization of health services during pregnancy such as the number of ANC visits and use of malaria prevention (use of IPTp-SP and bed net) was collected from participating women using a standardized questionnaire. Data on gestational age was not collected due to high likelihood of inaccuracy among illiterate mothers. Finger prick blood from mothers was used for blood smear and haemoglobin measurement. After birth, the umbilical cord was cut and clamped at about $3 \mathrm{~cm}$ from newborn abdomen. Umbilical cord blood was collected by releasing the clamp and compression and was used for parasitological studies. The newborns were dried and weighed. After placental expulsion, blood was collected from the maternal face and used to measure parasite density.

\section{Laboratory methods}

Thin and thick blood smears of maternal peripheral or cord blood and thin blood smears of placental blood were stained with $10 \%$ Giemsa dye and examined under oil immersion for parasites. Parasite density was determined by counting asexual forms of the parasite per 200 leukocytes and calculating parasites $\mu \mathrm{L}^{-1}$ by assuming an average of 8000 leukocytes $\mu \mathrm{L}^{-1}$ of blood. A slide was considered negative if no parasite was found after counting 500 leukocytes. Parasitaemia was classified as low ( $<500$ parasite $\mu \mathrm{L}^{-1}$ of blood), moderate (501-5000 parasites $\mu \mathrm{L}^{-1}$ of blood) and high (>5000 parasites $\mu \mathrm{L}^{-1}$ of blood) (Tonga et al. 2013). All the slides were double-checked blindly and for discrepant results a third consensus reading was performed.

Haemoglobin concentration was measured using a haemoglobinometer (HaemoCue AB, Angelhom, Sweden). Anaemia was defined as a haemoglobin concentration lower than $11 \cdot 0 \mathrm{~g} \mathrm{dL}^{-1}$.

\section{Sample size}

The expected number of pregnancies in the two primary health facilities was 2400 in 2010 . The sample size calculation $(n=320)$ was based on a prevalence of placental $P$. falciparum parasitaemia of $4 \%$ (Bamba et al. 2013) with a relative precision of $2 \%$ and alpha of $5 \%$.

\section{Data entry statistical analyses}

Data were double entered in Excel 2013 and analyses performed using STATA 12 (Stata Corp., College Station, Texas, USA).

Utilization of IPTp-SP was dichotomized into $<2$ doses $v s \geq 2$ doses. LBW was defined for $<2500 \mathrm{~g}$. Statistical calculations relied purposely on the Log10 of parasite density.

Proportions for categorical variables were compared with Pearson-chi2 test. Means comparisons between groups were done by the Student's $t$-test or One-way analysis of variance (ANOVA) test. When at least one of the group means was different from the other group means by using One-way ANOVA test, then a Tukey post hoc test was used to determine which groups differed from each other. Correlation between continuous variables was measured with Pearson correlation coefficient. We used logistic regression models to identify categorical variables associated with placental P. falciparum parasitaemia. Associations between placental parasitaemia and categorical variables (anaemia and LBW) and continuous variables (haemoglobin concentration and birthweight) were investigated by logistic and linear regression, respectively. Multivariable analyses were built using forward stepwise regression models, with an inclusion criterion of $P<0 \cdot 2$. Statistical significance was set for $P<0 \cdot 05$.

\section{Ethical considerations}

This study was approved by the National Ethics Committee for Health Research, Ouagadougou Burkina Faso (NECHR, Ouagadougou, BF No 2010-054). A written informed consent was obtained 
from all study participants prior to their enrolment. For illiterate delivering women, the informed consent discussion process was witnessed by an impartial individual, and the informed consent form was endorsed with a thumbprint. Women with moderate anaemia were treated with folic acid supplementation; those who had placental $P$. falciparum malaria received oral quinine at a dose of $24 \mathrm{mg}$ day $^{-1}$ for 7 days as recommended by the national malaria control program in Burkina Faso.

\section{RESULTS}

\section{Description of study participant}

A total of 320 mother-newborn pairs were included into the study. The mean maternal age was $24 \cdot 2 \pm$ $5 \cdot 6$ years. The median number of ANC visits was 3 (ranged from 0 to 5 ) and over $33 \%$ of mothers attended at least $4 \mathrm{ANC}$ visits. A total of 8 participants $(2 \cdot 5 \%)$ did not receive any dose of IPTp-SP during pregnancy, while $79 \%$ of participants received $\geq 2$ doses (Table 1 ). About $48 \%$ of women reported sleeping under a bed net and among them only $59 \cdot 7 \%$ used insecticide-treated net (ITN).

\section{Maternal and placental parasitaemia}

Overall, malaria parasite was found in $55(17 \cdot 2 \%)$ peripheral blood films and $29(9 \cdot 1 \%)$ placental blood films. Plasmodium falciparum was the sole species found in all cases. Both trophozoite and schizont forms of $P$. falciparum were found in

Table 1. Baseline characteristics of the study population

\begin{tabular}{|c|c|c|}
\hline Characteristic & Category & Value \\
\hline $\begin{array}{l}\text { Mean age } \\
\text { (years } \pm \text { S.D.) }\end{array}$ & & $24 \cdot 2 \pm 5 \cdot 6$ \\
\hline \multirow{3}{*}{ Age (years) } & $<20$ & $67(20 \cdot 9)$ \\
\hline & $20-24$ & $117(36 \cdot 6)$ \\
\hline & $\geq 20$ & $136(42 \cdot 5)$ \\
\hline \multicolumn{3}{|l|}{ Education } \\
\hline & No formal schooling & $180(56 \cdot 0)$ \\
\hline & Formal schooling & $140(44 \cdot 0)$ \\
\hline \multicolumn{3}{|l|}{ Gravidity } \\
\hline & Primigravida & $99(30 \cdot 9)$ \\
\hline & Secundigravida & $93(29 \cdot 1)$ \\
\hline & Multigravida & $128(40 \cdot 0)$ \\
\hline \multicolumn{3}{|c|}{ Number of ANC visits } \\
\hline & $\leq 2$ & $77(24 \cdot 1)$ \\
\hline & 3 & $137(42 \cdot 8)$ \\
\hline & $\geq 4$ & $106(33 \cdot 1)$ \\
\hline $\begin{array}{l}\text { Median ANC visits } \\
\text { (IQR) }\end{array}$ & & $3(1)$ \\
\hline \multirow[t]{2}{*}{$\mathrm{SP}$ dose } & $<2$ & $67(20 \cdot 9)$ \\
\hline & $\geq 2$ & $253(79 \cdot 1)$ \\
\hline \multirow[t]{2}{*}{ Use of bed net } & $\overline{\mathrm{No}}$ & $166(51 \cdot 9)$ \\
\hline & Yes & $154(48 \cdot 1)$ \\
\hline \multirow{2}{*}{ Use of ITN } & No & $62(40 \cdot 3)$ \\
\hline & Yes & $92(59 \cdot 7)$ \\
\hline
\end{tabular}

placental blood samples. Among the 55 peripheral blood samples, both forms of $P$. falciparum were found in only one sample. Of the 320 women, 26 $(8 \cdot 1 \%)$ women had concurrent peripheral and placental parasitaemia, $29(9 \cdot 0 \%)$ women had peripheral infections only, while $3(0 \cdot 9 \%)$ had placental infection only. The arithmetic mean parasite density in placental blood $\left(4.5 \pm 0.8 \mu \mathrm{L}^{-1}\right)$ was significantly higher than that in peripheral $\left(3 \cdot 7 \pm 0 \cdot 7 \mu \mathrm{L}^{-1}\right)(P<$ $0 \cdot 001)$. The proportion of placenta with high parasite density $\left(>5000 \mu \mathrm{L}^{-1}\right)$ is higher compared with that of peripheral blood with high parasite density $(P=0 \cdot 01)$. Peripheral blood parasite density correlated well with placental blood parasite density $(r=0.49, \quad P=0.01)$. The Tukey post-hoc test revealed that mean parasite density in peripheral blood was statistically significantly lower in the multigravida group compared with the primigravida group $\left(-0 \cdot 5 \pm 0 \cdot 2\right.$ parasite $\left.\mu \mathrm{L}^{-1}, P=0 \cdot 04\right)$. However, there were no statistically significant differences between the multigravida and secundigravida groups $\left(-0 \cdot 2 \pm 0 \cdot 2\right.$ parasite $\left.\mu \mathrm{L}^{-1}, P=0 \cdot 6\right)$, or the secundigravida and primigravida groups $(-0.4 \pm$ $0 \cdot 2$ parasite $\left.\mu \mathrm{L}^{-1}, \quad P=0 \cdot 3\right)$. The mean parasite density in placental blood was not statistically significant different between gravidity groups $(F(2,26)=1 \cdot 75, P=0 \cdot 2)$.

Overall, the univariable regression analysis showed that primigravida (OR: $3 \cdot 6 ; 95 \%$ CI $(1 \cdot 4-$ $9 \cdot 7)$ ) and women who did not sleep under bed net (OR: $2 \cdot 6$; 95\% CI $(1 \cdot 1-6 \cdot 2)$ ) were at higher odds of P. falciparum placental parasitaemia (Table 2 ). The use of IPTp-SP was not associated with the prevalence of placental malaria infection. These potential factors were further subjected to multivariable logistic regression. Finally, primigravida and women who did not sleep under bed net had 3.5- and 2.6folds increased odds of placental malaria infection, respectively.

\section{Effect of placental P. falciparum parasitaemia on maternal outcomes}

The proportion of anaemia among all women was $48 \cdot 4 \%$. The prevalence of anaemia was significantly higher in women with placental malaria parasitaemia $(72 \cdot 4 \%)$ than in uninfected women $(46 \cdot 1 \%)$. Placental malaria parasitaemia was associated with a $3 \cdot 1$-folds increase odds of maternal anaemia (aOR: $3 \cdot 1 ; 95 \%$ CI (1·3-7·4)) (Table 3). The mean haemoglobin level among study participant was $10 \cdot 9 \pm 1 \cdot 7 \mathrm{~g} \mathrm{dL}^{-1}$ and infected women had $0 \cdot 8 \mathrm{~g} \mathrm{dL}^{-1}$ lower than uninfected women $(P=0 \cdot 01)$ ('Table 4$)$.

\section{Effect of placental P. falciparum parasitaemia on newborn outcomes}

The overall prevalence of malaria parasite infection in newborns was $0.9 \%(3 / 320)$. The prevalence of 
Table 2. Risk factors associated with placental parasitaemia among delivering women in Bobo-Dioulasso

\begin{tabular}{lclll}
\hline \hline Potential factors & Placental parasitaemia & Crude OR $(95 \% \mathrm{CI})$ & Adjusted OR $(95 \% \mathrm{CI})$ & $P$ \\
\hline Age & & & & $0 \cdot 9$ \\
$\quad<20$ & $14 \cdot 9(10 / 67)$ & $2 \cdot 2(0 \cdot 95-4 \cdot 90)$ & $1 \cdot 0(0 \cdot 4-2 \cdot 9)$ & - \\
$\quad 20$ & $7 \cdot 5(19 / 253)$ & 1 & 1 & - \\
Gravidity & $4 \cdot 7(6 / 128)$ & 1 & $2 \cdot 3(0 \cdot 8-7 \cdot 1)$ & $0 \cdot 1$ \\
$\quad$ Multigravida & $8 \cdot 6(8 / 93)$ & $1 \cdot 9(0 \cdot 6-5 \cdot 7)$ & $3 \cdot 5(1 \cdot 1-11 \cdot 2)$ & $0 \cdot 04$ \\
$\quad$ Secundigravida & $15 \cdot 2(15 / 99)$ & $3 \cdot 6(1 \cdot 4-9 \cdot 7)$ & & \\
$\quad$ Primigravida & $10 \cdot 5(7 / 67)$ & 1 & - & - \\
IPTp-SP dose & $8 \cdot 7(22 / 253)$ & $0 \cdot 8(0 \cdot 3-2 \cdot 0)$ & & \\
$\quad 0-1$ & $5 \cdot 2(8 / 154)$ & 1 & $2 \cdot 6(1 \cdot 1-6 \cdot 3)$ & \\
$\quad \geq 2$ & $12 \cdot 7(21 / 166)$ & $2 \cdot 6(1 \cdot 1-6 \cdot 2)$ & & \\
Bed net use & & & & \\
$\quad$ Yes & &
\end{tabular}

Table 3. Effect of placental malaria on maternal anaemia and low birthweight in multivariable logistic regression analysis

\begin{tabular}{lll}
\hline \hline Variable & Adjusted OR $(95 \% \mathrm{CI})$ & $P$ \\
\hline Anaemia $^{\mathrm{a}}$ & & \\
Placental malaria & $3 \cdot 1(1 \cdot 3-7 \cdot 4)$ & $0 \cdot 01$ \\
$\quad$ Yes & 1 & - \\
$\quad$ No & & \\
LBW & & $0 \cdot 9+$ \\
Placental malaria & $1 \cdot 0(0 \cdot 3-3 \cdot 2)$ & - \\
$\quad$ Yes & 1 & $<0 \cdot 001$ \\
$\quad$ No & & $0 \cdot 03$ \\
Gravidity & $8 \cdot 6(2 \cdot 8-26 \cdot 7)$ & - \\
$\quad \begin{array}{l}\text { Primigravida } \\
\text { Secundigravida }\end{array}$ & $3 \cdot 3(1 \cdot 1-9 \cdot 9)$ & \\
$\quad$ Multigravida & 1 & \\
\hline \hline
\end{tabular}

${ }^{\text {a }}$ Regression analysis adjusted by age, gravidity, use of IPTp-SP, and use of bed net.

b Regression analysis adjusted by newborn's gender.

congenital malaria parasitaemia was $10 \cdot 3 \%(3 / 29)$ among infants born to mothers with placental malaria parasitaemia. The three newborns were infected by the trophozoite forms of $P$. falciparum with parasite density ranging from 200 to 1120 $\mu \mathrm{L}^{-1}$. The mothers of the newborns had both high peripheral and placental malaria parasitaemia as shown in Table 5. Furthermore, they have benefited from at least 2 doses of IPTp-SP and two of them were primigravida.
Overall, the mean singleton live-born birth weight was $2917 \pm 426 \mathrm{~g}$ (Table 4). A total of 37 neonates $(11 \cdot 6 \%)$ had LBW. The prevalence of LBW was higher among babies born from women with placental parasitaemia $(13 \cdot 8 \%)$ compared with those without $(11 \cdot 3 \%)(P>0 \cdot 05)$. Factors associated with LBW in multivariable analysis were primigravidity $(\mathrm{aOR}=8 \cdot 6 ; 95 \% \mathrm{CI}(2 \cdot 8-26 \cdot 7))$ and secundigravidity $(\mathrm{aOR}=3 \cdot 3 ; 95 \%$ CI $(1 \cdot 1-9 \cdot 9))$ (Table 3$)$. Neonates born from mothers with placental malaria parasitaemia had a significant mean birthweight reduction of $200 \mathrm{~g}$ compared with those born from mothers without placental malaria parasitaemia (Table 4). In addition, there was a significant negative correlation between birthweight and maternal parasitaemia density $(r=0.32 ; P=0.02)$. In contrast, there was no correlation between placental malaria parasitaemia density and birthweight of the newborns $(r=0 \cdot 08 ; P=0 \cdot 7)$.

\section{DISCUSSION}

The aim of this study was to determine the prevalence and the impact of placental malaria parasitaemia on maternal anaemia, congenital malaria infection and birthweight in periurban area of Bobo-Dioulasso.

The overall prevalence of placental malaria parasitaemia $(9 \cdot 1 \%)$ was higher than the reported prevalence $(4.7 \%)$ in urban area of Bobo-Dioulasso by

Table 4. Effect of placental malaria on maternal haemoglobin concentration and birthweight in multivariable linear regression analysis

\begin{tabular}{|c|c|c|c|c|c|}
\hline \multirow[b]{2}{*}{ Variable } & \multirow{2}{*}{$\begin{array}{l}\text { All women } \\
(N=320)\end{array}$} & \multicolumn{2}{|l|}{ Placental malaria } & \multirow[b]{2}{*}{ Adjusted coefficient } & \multirow[b]{2}{*}{$P$} \\
\hline & & Positive $(n=29)$ & Negative $(n=291)$ & & \\
\hline Mean haemoglobin ( $\mathrm{g} \mathrm{dL}^{-1}$, \pm s.D. $)$ & $10 \cdot 9 \pm 1 \cdot 7$ & $10 \cdot 2 \pm 1 \cdot 7$ & $11 \cdot 0 \pm 1 \cdot 7$ & $-0 \cdot 8$ & $0 \cdot 01^{\mathrm{a}}$ \\
\hline Mean birthweight ( $\mathrm{g} \pm \mathrm{s} . \mathrm{D})$. & $2917 \pm 426$ & $2700 \pm 384$ & $2939 \pm 424$ & -200 & $0 \cdot 02^{\mathrm{b}}$ \\
\hline
\end{tabular}

a Regression analysis adjusted by age, gravidity, use of IPTp-SP, and use of bed net.

b Regression analysis adjusted by age, gravidity, use of IPTp-SP, use of bed net and newborn's gender. 
Table 5. Distribution of the 3 cases of congenital malaria according to their mothers' age, obstetric history and malaria infection

\begin{tabular}{|c|c|c|c|}
\hline Characteristic & Case 1 & Case 2 & Case 3 \\
\hline Age & 23 & 23 & 17 \\
\hline Gravidity & 1 & 2 & 1 \\
\hline ANC visits & 3 & 3 & 3 \\
\hline Doses of IPTp-SP & 2 & 2 & 2 \\
\hline Timing between the last dose of IPTp and delivery (day) & 90 & 47 & 103 \\
\hline Use of bed net & No & No & No \\
\hline Parasite density in peripheral blood (parasite $\mu \mathrm{L}^{-1}$ ) & 169000 & 12720 & 15600 \\
\hline Parasite density in placental blood (parasite $\mu \mathrm{L}^{-1}$ ) & 178320 & 132000 & 150000 \\
\hline
\end{tabular}

(Bamba et al. 2013). This could be explained by the location of our study sites in the periurban area of Bobo-Dioulasso where the transmission of malaria is thought to be higher than in the urban part of the town (Diabaté, 2003). This trend is consistent with previous reports in this town where the prevalence in periurban area of the town was $29 \%$ in 1984 and $18 \%$ in 1991 compared with those of the urban part in 1984 (9\%) and in 1991 (13\%) (Molez et al. 1992; Gazin et al. 1994). As can be seen, there was a trend of decrease of the prevalence of placental infection over the years probably due to the increase in malaria prevention measures coverage. Our findings are lower than those reported in rural area of Burkina Faso ranging from 15.9 to 22.7\% (Sirima et al. 2006; Gies et al. 2008, 2009; Tiono et al. 2009). The higher observed rates in rural area could be explained by the high transmission level of malaria in rural area of Burkina Faso (Diabaté, 2003). The prevalence of placental malaria parasitaemia in urban and periurban settings in Africa varied from 1.6 to $69 \cdot 6 \%$ (Morgan, 1994; Ndao et al. 2003; Sarr et al. 2006; Namusoke et al. 2010; Famanta et al. 2011; Ezebialu et al. 2012; Bassey et al. 2015). The wide ranges in reported prevalence of placental malaria infection may be due to multiple factors. First, one factor is the method of diagnosis. Indeed most of the studies (Sarr et al. 2006; Namusoke et al. 2010; Ezebialu et al. 2012) had used placental histology, which is recognized as the gold standard test and more sensitive than microscopy (Kattenberg et al. 2011). Second, other factors that may explain this variation include intensity of transmission, study population characteristics (age, parity, HIV status), use of preventive measures (IPTpSP, ITNs) (Mokuolu et al. 2009).

We observed 32 discordant results between placental and peripheral parasitaemia and this is consistent with previous reports (Matteelli et al. 1994; Ezebialu et al. 2012). Placental parasitaemia without peripheral parasitaemia may be a feature in women who have previously been treated with clearance of peripheral parasite whereas peripheral parasitaemia without placental infection may occur in early malaria infection, especially if parasitaemia is low (Ezebialu et al. 2012).

Malaria infection with parasite density higher than 5000 parasites $\mu \mathrm{L}^{-1}$ was significantly higher in placental blood than in peripheral blood. Parasites variant antigens expressed on the surface of infected erythrocytes results in a preferential sequestration of parasitized red blood cells in the placenta, with subsequent increase on malaria parasite density even in the absence of peripheral blood parasitaemia (Staalsoe et al. 2001; Brabin et al. 2004).

This study demonstrated that primigravida are $3 \cdot 5$ times more likely to have placental malaria than multigravida. Pregnancy is associated with a decrease in immunity, which is more pronounced in primigravida than in multigravida. Indeed, Primigravida express specific placental receptors that facilitate binding of parasitize erythrocytes to the placental tissue, but this is less likely in the multigravida due to acquisition of specific antibodies that prevent such binding from occurring (Staalsoe et al. 2001; Brabin et al. 2004).

The use of bed nets was associated with reduced odds of placental malaria parasitaemia despite a low coverage of ITNs. Educating pregnant women on the role of ITNs in preventing malaria will impact positively in reducing the prevalence of malaria. Furthermore, government should intensify efforts in ensuring that ITNs are readily available at all health facilities and ITNs should be distributed to all pregnant women especially primigravida during ANC visits in order to encourage its utilization.

Placental malaria in this study was associated with increased odds of maternal anaemia. Anaemia remains the most frequent consequence of malaria during pregnancy irrespective of transmission level and pre-pregnancy level of malaria immunity (Menendez, 1995). However, it is difficult to attribute this prevalence of anaemia solely to the effect of malaria parasitaemia as other causes such as helminthiasis, malnutrition, HIV infection and sickle cell anaemia were not assessed in our study.

In our study IPTp-SP use was based on documentation from antenatal cards. That is not likely 
accurate given that its administration is not often directly observed in the antenatal clinic affecting hence compliance with IPTp-SP. Poor compliance with IPTp-SP may subsequently explain the fact that the use of at least 2 doses of IPTp-SP was not associated with a reduction of the prevalence of placental malaria infection in the study population. However many studies have shown IPTp-SP to be highly effective in reducing placental malaria infection in pregnant women in Burkina Faso (Sirima et al. 2006; Gies et al. 2008, 2009; Tiono et al. 2009) and in Africa (van Eijk et al. 2004; Aziken et al. 2011; Vanga-Bosson et al. 2011). The inconsistent findings on the protective effect of IP'Tp-SP against placental malaria parasitaemia have been reported in Cameroon (Tonga et al. 2013), Tanzania (Harrington et al. 2011) and Uganda (Arinaitwe et al. 2013). The prevalence of quadruple mutation (combined triple Pfdhfr mutation $(51+59+108)$ and Pfdhps 437 mutation) in pregnant women was $31 \cdot 6 \%$ in Bobo-Dioulasso (unpublished observations). Therefore, further studies need to be carried out to establish whether the inconsistency of IPTp-SP effect is attributable to loss of SP efficacy in our study area or not.

The prevalence of congenital malaria in our study $(0.9 \%)$ was very low compared with that previously reported in rural area of Burkina Faso (1.4\%) by (Ouédraogo et al. 2012). The prevalence of congenital malaria assessed by microscopy in sub-Saharan Africa has been reported to vary from $0 \cdot 4$ to $54 \cdot 2 \%$ (Falade et al. 2007; Mwaniki et al. 2010; Enweronu-laryea et al. 2013; Tonga et al. 2013). The mothers of the three infected newborns are primigravida and secundigravida. It has been shown that primigravida and secundigravida with placental malaria parasitaemia are at increased risk for congenital infection (Malhotra et al. 2006; Okafor et al. 2006). Indeed, the low maternal malarial IgG antibodies transferred to the fetus during pregnancy due to poor immunity to malaria in mothers is a plausible explanation to transplacental transmission of the parasite from mother to child (Taylor and Siddiqui, 1982). The three mothers had benefited from the doses of IPTp-SP according to the WHO guidelines (WHO, 2004). However, all of them were infected and their babies as well. This observation could be explained by a poor observance of chaemoprophylaxis or a resistance of $P$. falciparum to SP. The strong correlation between peripheral and placental parasitaemia and the occurrence congenital malaria infection previously reported by (Redd et al. 1996; Okafor et al. 2006; Ouédraogo et al. 2012) has been confirmed in this study. Therefore, babies born from mothers with malaria should be screened for congenital malaria.

The overall prevalence of LBW (11.6\%) was similar to the prevalence reported from health facilities in Bobo-Dioulasso in 2013 (10.9\%) (Ministry of
Health of Burkina Faso, 2014). The prevalence of LBW tended to be higher in babies born from mothers with placental malaria parasitaemia compared with that of babies born from uninfected mothers although such difference did not reach statistical significance. The more likely explanation is that our small sample size might have not provided enough strength to our statistics. However previous studies in Africa had found an association between placental malaria parasitaemia and LBW and had defined placental malaria parasitaemia as a predictor of LBW (Menendez et al. 2000; Shulman et al. 2001; Akanbi et al. 2009). In this study, primigravida and secundigravida were at higher odds of LBW than multigravida. This is consistent with several reports in Africa (Akum et al. 2005; Sirima et al. 2006; Gies et al. 2009). IP'Tp-SP was not associated with a reduction in LBW as shown in Ivory Coast (Vanga-Bosson et al. 2011), in Cameroon ('Tonga et al. 2013) and in Uganda (Arinaitwe et al. 2013). However, some studies had shown that the use of IPTp-SP reduced significantly the prevalence of LBW (Sirima et al. 2006; Gies et al. 2008, 2009; Tiono et al. 2009). The gestational age of women when first dosed of IPTp-SP was given as well as other factors that could explain the occurrence of LBW such as women nutritional status were not collected in this study. This makes the comparison between our study and others difficult.

Although the major strengths of this study were that the study design and the sample size were adequate to estimate the prevalence of placental malaria parasitaemia among the study population we do acknowledge some limitations. First, the selected health facilities may not be representative of all delivery facilities across Burkina Faso. Second, we were unable to obtain accurate data on gestational age limiting hence the assessment of the impact of placental malaria on gestational age.

\section{Concluding remarks}

Placental malaria is frequent particularly in primigravida. The results of our study have confirmed that placental malaria parasitaemia is still an important cause of morbidity in pregnancy in BoboDioulasso. We found no evidence for an association between the number of SP doses and the outcome of pregnancy despite a high IPTp-SP coverage. The use of bed nets was linked with a lower level of placental malaria. Delivery of insecticide-treated bed nets should be therefore emphasized in primigravida to reduce the burden of malaria in pregnancy.

\section{ACKNOWLEDGEMENTS}

We thank all midwives and pregnant women of both Kua and Lafiabougou health centers. 


\section{FINANCIAL SUPPORT}

This work was supported by the Université Polytechnique de Bobo-Dioulasso as part of Mamoudou Cisse's PhD project.

\section{CONFLICT OF INTEREST}

None.

\section{ETHICAL STANDARDS}

The authors assert that all procedures contributing to this work comply with the ethical standards of the Ministry of Health of Burkina Faso.

\section{REFERENCES}

Akanbi, O. M., Odaibo, A. B. and Ademowo, O. G. (2009). The burden of malaria infection on pregnant women and birth weight of infants in South Western Nigeria. East Africa Fournal of Public Health 6, 63-68. Akum, A. E., Anchang, J. K., Jacob, T. M., Boyo, M. A., Mokube, J. A. and Marita, T. (2005). The effect of maternal, umbilical cord and placental malaria parasitaemia on the birthweight of newborns from SouthWestern Cameroon. Acta Paediatrica 94, 917-923.

Arinaitwe, E., Ades, V., Walakira, A., Ninsiima, B., Mugagga, O., Patil, T. S., Schwartz, A., Kamya, M. R., Nasr, S., Chang, M., Filler, S. and Dorsey, G. (2013). Intermittent preventive therapy with sulfadoxine-pyrimethamine for malaria in pregnancy: a Cross-sectional study from Tororo, Uganda. PLoS ONE 8, e73073.

Aziken, M. E., Akubuo, K. K. and Gharoro, E. P. (2011). Efficacy of intermittent preventive treatment with sulfadoxine-pyrimethamine on placental parasitemia in pregnant women in Midwestern Nigeria. International Fournal of Gynaecology and Obstetrics 112, 30-33.

Bamba, S., Séré, A., Nikiéma, R., Halidou, T., Thiéba, B., Dao, B. and Guiguemdé, R. T. (2013). Intermittent preventive treatment with sulfadoxine-pyrimethamine for malaria in pregnant women: efficacy and compliance in two urban hospitals in Burkina Faso. Pan African Medical Fournal 14, 105.

Bassey, G., Nyengidiki, T. K. and John, C. T. (2015). Prevalence of placenta plasmodium parasitemia and pregnancy outcome in asymptomatic patients at delivery in a University Teaching Hospital in Nigeria. Nigerian Fournal of Clinical Practice 18, 27-32.

Brabin, B. J., Romagosa, C., Abdelgalil, S., Menéndez, C., Verhoeff, F. H., McGready, R., Fletcher, K. A., Owens, S., D'Alessandro, U., Nosten, F., Fischer, P. R. and Ordi, J. (2004). The sick placenta-the role of malaria. Placenta 25, 359-378.

Desai, M., ter Kuile, F. O., Nosten, F., McGready, R., Asamoa, K., Brabin, B. and Newman, R. D. (2007). Epidemiology and burden of malaria in pregnancy. Lancet Infectious Diseases 7, 93-104

Diabaté, A. (2003). Le paludisme au Burkina Faso: étude de la transmission et répartition géographique de la résistance d'anopheles gambiae sl aux pyréthrinoïdes. Thèse de $\mathrm{PhD}$, Université de Montpellier II, Montpellier, France.

Enweronu-laryea, C. C., Adjei, G. O., Mensah, B., Duah, N. and Quashie, N. B. (2013). Prevalence of congenital malaria in high-risk Ghanaian newborns : a cross-sectional study. Malaria fournal 12, 17.

Ezebialu, I. U., Eke, A. C., Ezeagwuna, D. A., Nwachukwu, C. E., Ifediata, F. and Ezebialu, C. U. (2012). Prevalence, pattern, and determinants of placental malaria in a population of Southeastern Nigerian parturients. International Fournal of Infectious Diseases 16, e860-e865.

Falade, C., Olugbenga, M., Henrietta, O., Adeola, O., Adegoke, F., Tagbo, O., Maman, A., Davidson, H. H. and Michael, V. C. (2007). Epidemiology of congenital malaria in Nigeria: a multi-centre study. Tropical Medicine and International Health 12, 1279-1287.

Famanta, A., Diakite, M., Diawara, S. I., Diakité, S. A., Doumbia, S., Traoré, K., Konaté, D. S., Doumbia, M., Keita, A. S., Thiéro, D., Traoré, S. F., Doumbia, S. and Tounkara, A. (2011). Prévalence du paludisme maternel, placentaire et du petit poids de naissance au cours du travail d'accouchement et en post-partum en milieu périurbain à Bamako (Mali). Santé 21, 3-7.

Gazin, P. P., Compaoré, M. P., Hutin, Y. and Molez, J. F. (1994). Infection du placenta par les plasmodium en zone d'endémie. Les facteurs de risque. Bulletin de la Société de Pathologie Exotique 87, 97-100.
Gies, S., Coulibaly, S. O., Ouattara, F. T., Ky, C., Brabin, B. J. and D'Alessandro, U. (2008). A community effectiveness trial of strategies promoting intermittent preventive treatment with sulphadoxine-pyrimethamine in pregnant women in rural Burkina Faso. Malaria fournal 7, 180. Gies, S., Coulibaly, S. O., Ouattara, F. T. and D'Alessandro, U. (2009). Individual efficacy of intermittent preventive treatment with sulfadoxine-pyrimethamine in Primi- and secundigravidae in rural Burkina Faso: impact on parasitaemia, anaemia and birth weight. Tropical Medicine and International Health 14, 174-182.

Guyatt, H. L. and Snow, R. W. (2004). Impact of malaria during pregnancy on low birth weight in Sub-Saharan Africa. Clinical Microbiology Reviews 17, 760-769.

Harrington, W. E., Mutabingwa, T. K., Kabyemela, E., Fried, M. and Duffy, P. E. (2011). Intermittent treatment to prevent pregnancy malaria does not confer benefit in an area of widespread drug resistance. Clinical Infectious Diseases 53, 224-230.

Kattenberg, J. H., Ochodo, E. A., Boer, K. R., Schallig, H. D., Mens, P. F. and Leeflang, M. M. (2011). Systematic review and metaanalysis: rapid diagnostic tests versus placental histology, microscopy and PCR for malaria in pregnant women. Malaria fournal 10, 321.

Malhotra, I., Mungai, P., Muchiri, E., Kwiek, J. J., Meshnick, S. R. and King, C. L. (2006). Umbilical cord-blood infections with Plasmodium falciparum malaria are acquired antenatally in Kenya. Fournal of Infectious Diseases 194, 176-183.

Matteelli, A., Donato, F., Muchi, J. A., Leopardi, O., Astroli, L. and Carosi, G. (1994). Malaria and anaemia in pregnant women in urban Zanzibar, Tanzania. Annals of Tropical Medicine and Parasitology 88, $475-483$.

Menendez, C. (1995). Malaria during pregnancy: a priority area of malaria research and control. Parasitology Today 11, 178-183.

Menendez, C., Ordi, J., Ismail, M. R., Ventura, P. J., Aponte, J. J., Kahigwa, E. and Font, F. (2000). The impact of placental malaria on gestational age and birth weight. Fournal of Infectious Diseases 181, 1740-1745. Ministry of Health of Burkina Faso (2014). Annuaire Statistique 2013. http://www.cns.bf/IMG/pdf/annuaire_sante_2013.pdf.

Mokuolu, O. A., Falade, C. O., Orogade, A. A., Okafor, H. U., Adedoyin, O. T., Oguonu, T. A., Dada-Adegbola, H. O., Oguntayo, O. A., Ernest, S. K., Hamer, D. H. and Callahan, M. V. (2009). Malaria at parturition in Nigeria: current status and delivery outcome. Infectious Diseases in Obstetrics and Gynecology 2009, 7.

Molez, J. F., Bosseno, M. F., Traore, G., Carnevale, P. and Gazin, P. (1992). Infection placentaire et paludisme urbain à Bobo-Dioulasso, Burkina Faso. Cahiers Santé 2, 176-179.

Morgan, H. G. (1994). Placental malaria and low birthweight neonates in urban Sierra Leone. Annals of Tropical Medicine and Parasitology 88, $575-580$.

Mwaniki, M. K., Talbert, A. W., Mturi, F. N., Berkley, J. A., Kager, P., Marsh, K. and Newton, C. R. (2010). Congenital and neonatal malaria in a rural Kenyan district hospital: an eight-year analysis. Malaria Fournal 9, 313.

Namusoke, F., Rasti, N., Kironde, F., Wahlgren, M. and Mirembe, F. (2010). Malaria burden in pregnancy at Mulago national referral hospital in Kampala, Uganda. Malaria Research and Treatment 2010, 10.

Ndao, C. T., Ndiaye, J. L., Gaye, A. and Le Hesran, J. Y. (2003). Infection du placenta par Plasmodium falciparum en zone urbaine au Sénégal. Bulletin de la Société de Pathologie Exotique 96, 161-164.

Okafor, U. H., Oguonu, T. and Onah, H. E. (2006). Risk factors associated with congenital malaria in Enugu, South Eastern Nigeria. Fournal of Obstetrics and Gynaecology 26, 612-116.

Ouédraogo, A., Tiono, A. B., Diarra, A., Bougouma, E. C., Nébié, I., Konaté, A. T. and Sirima, S. B. (2012). Transplacental transmission of Plasmodium falciparum in a highly malaria endemic area of Burkina Faso. Fournal of Topical Medicine 2012, 7 .

Redd, S. C., Wirima, J. J., Steketee, R. W., Breman, J. G. and Heymann, D. L. (1996). Transplacental transmission of Plasmodium falciparum in rural Malawi. American Fournal of Tropical Medicine and Hygiene 55, 57-60.

Sarr, D., Marrama, L., Gaye, A., Dangou, J. M., Niang, M., Mercereau-Puijalon, O., Lehesran, J. Y. and Jambou, R. (2006). High prevalence of placental malaria and low birth weight in sahelian periurban area. American Fournal of Tropical Medicine and Hygiene 75, 171-177.

Shulman, C. E., Marshall, T., Dorman, E. K., Bulmer, J. N., Cutts, F., Peshu, N. and Marsh, K. (2001). Malaria in pregnancy: adverse effects on haemoglobin levels and birthweight in primigravidae and multigravidae. Tropical Medicine and International Health 6, 770-778.

Sirima, S. B., Cotte, A. H., Konaté, A., Moran, A. C., Asamoa, K., Bougouma, E. C., Diarra, A., Ouédraogo, A., Parise, M. E. and 
Newman, R. D. (2006). Malaria prevention during pregnancy: assessing the disease burden one year after implementing a program of intermittent preventive treatment in Koupela district, Burkina Faso. American fournal of Tropical Medicine and Hygiene 75, 205-211.

Staalsoe, T., Megnekou, R., Fievét, N., Ricke, C. H., Zornig, H. D., Leke, R., Taylor, D. W., Deloron, P. and Hviid, L. (2001). Acquisition and decay of antibodies to pregnancy-associated variant antigens on the surface of Plasmodium falciparum-infected erythrocytes that protect against placental parasitemia. Fournal of Infectious Diseases 184, 618-626.

Steketee, R. W., Nahlen, B. L., Parise, M. E. and Menendez, C. (2001). The burden of malaria in pregnancy in malaria-endemic areas. American Fournal of Tropical Medicine and Hygiene 64, 28-35.

Taylor, D. W. and Siddiqui, W. A. (1982). Recent advances in malarial immunity. Annual Review of Medicine 33, 69-96.

Tiono, A. B., Ouedraogo, A., Bougouma, E. C., Diarra, A., Konaté, A. T., Nébié, I. and Sirima, S. B. (2009). Placental malaria and low birth weight in pregnant women living in a rural area of Burkina Faso following the use of three preventive treatment Regimens. Malaria fournal 8, 224. Tonga, C., Kimbi, H. K., Anchang-Kimbi, J. K., Nyabeyeu, H. N., Bissemou, Z. B. and Lehman, L. G. (2013). Malaria risk factors in women on intermittent preventive treatment at delivery and their effects on pregnancy outcome in Sanaga-Maritime, Cameroon. PLoS ONE 8 , e65876.

Van Eijk, A. M., Ayisi, J. G., ter Kuile, F. O., Otieno, J. A. Misore, A. O., Odondi, J. O., Rosen, D. H., Kager, P. A. Steketee, R. W. and Nahlen, B. L. (2004). Effectiveness of intermittent preventive treatment with sulphadoxine-pyrimethamine for control of malaria in pregnancy in Western Kenya: a hospital-based study. Tropical Medicine and International Health 9, 351-360.

Vanga-Bosson, H. A., Coffie, P. A., Kanhon, S., Sloan, C., Kouakou, F., Eholie, S. P., Kone, M., Dabis, F., Menan, H. and Ekouevi, D. K. (2011). Coverage of intermittent prevention treatment with sulphadoxine-pyrimethamine among pregnant women and congenital malaria in Côte D'Ivoire. Malaria fournal 10, 105.

World Health Organization (2004). A strategic framework for malaria prevention and control during pregnancy in the African Region. http:// www.who.int/malaria/publications/atoz/afr_mal_04_01/en.

World Health Organization (2012). Updated WHO policy recommendation (October 2012): intermittent preventative treatment of malaria in pregnancy using sulfadoxine-pyrimethamine (IPTp-SP). http://www.who.int/ malaria/iptp_sp_updated_policy_recommendation_en_102012.pdf. 